\title{
Electrophysiological responsiveness and clinical outcomes of local corticosteroid injection in the treatment of carpal tunnel syndrome
}

\author{
Responsividade eletrofisiológica e desfechos clínicos da injeção local de corticosteroide \\ no tratamento da síndrome do túnel do carpo
}

Devrimsel Harika ERTEM'1, Tuba Cerrahoglu SIRIN', Ilhan YILMAZ²

\begin{abstract}
Carpal tunnel syndrome (CTS) is the most common mononeuropathy caused by entrapment of the median nerve at the wrist. Common treatment options for CTS include oral analgesics, splinting, hand therapy, local injections with steroids or surgery. Objective: The aim of the present study was to assess the short-term clinical and electrophysiological outcomes of local corticosteroid injection (LCI) in patients with symptomatic CTS. Methods: Electrophysiological parameters were evaluated before and three months after LCl. Moreover, the Numeric Rating Scale (NRS), the Boston Symptom Severity Scale (SSS) and the Functional Status Scale (FSS) were administered before and after the injection. A mixture of $1 \mathrm{~mL}(40 \mathrm{mg}$ ) of methylprednisolone and $1 \mathrm{~mL}$ of $0.5 \%$ bupivacaine were injected blindly on the volar side of the forearm between the tendons of the radial carpal flexor muscle and long palmar muscle. Results: A total of 25 patients (45 hands) were enrolled in the study. Twenty women and five men with a mean age of $49.28 \pm 11.37$ years were included. A statistically significant difference was noted for improvement of sensory conduction velocities, sensory peak latency, and motor distal latency $(p=0.001)$ after LCI. A significant difference was recorded between pre- and post-injection for NRS, SSS and FSS scores $(p=0.000)$. Conclusion: Local corticosteroid injection for CTS provides a short-term improvement in neurophysiological and clinical outcomes such as pain intensity, symptom severity and functional ability.
\end{abstract}

Keywords: Carpal tunnel syndrome; median neuropathy; steroids; injections.

RESUMO

A síndrome do túnel do carpo (STC) é a mononeuropatia mais comum causada pelo aprisionamento do nervo mediano no punho. Opções comuns de tratamento para STC incluem analgésicos orais, splinting, terapia de mão, injeções locais com esteroides ou cirurgia. Objetivo: O objetivo do presente estudo foi avaliar os resultados clínicos e eletrofisiológicos de curto prazo da injeção de corticosteroide local (ICL) em pacientes com STC sintomática. Métodos: Os parâmetros eletrofisiológicos foram avaliados antes e três meses após a ICL. Além disso, a Escala Numérica de Avaliação (NRS), a Escala de Gravidade de Sintomas de Boston (BSS) e a Escala de Status Funcional (FSS) foram administradas antes e após a injeção. Uma mistura de $1 \mathrm{ml}$ (40 mg) de metilprednisolona e $1 \mathrm{ml}$ de bupivacaína a 0,5\% foi injetada cegamente no lado do antebraço entre os tendões do músculo flexor radial do carpo e o músculo palmar longo. Resultados: Um total de 25 pacientes (45 mãos) foi incluído no estudo. Vinte mulheres e cinco homens com idade média de 49,28 \pm 11,37 anos foram incluídos. Foi observada diferença estatisticamente significante para melhora das velocidades de condução sensitiva, latência de pico sensorial, latência motora distal $(p=0,001)$ após a ICL. Uma diferença significativa foi registrada entre pré e pós-injeção para os escores NRS, BSS e FSS ( $p=0,000)$. Conclusão: A ICL para STC fornece uma melhoria a curto prazo em resultados neurofisiológicos e clínicos, tais como intensidade da dor, gravidade dos sintomas e capacidade funcional.

Palavras-chave: Síndrome do tunel carpal; neuropatia mediana; esteroides; injeções.

${ }^{1}$ University of Health Sciences, Sisli Hamidiye Etfal Research and Training Hospital, Department of Neurology, Istanbul, Turkey.

${ }^{2}$ University of Health Sciences, Sisli Hamidiye Etfal Research and Training Hospital, Department of Neurosurgery, Istanbul, Turkey.

Devrimsel Harika Ertem (iD https://orcid.org/0000-0001-5309-1258; Tuba Cerrahoglu Sirin iD https://orcid.org/0000-0003-4412-8105; Ilhan Yilmaz

https://orcid.org/0000-0001-5548-2228

Correspondence: Devrimsel Harika Ertem; Halaskargazi Cad. Etfal Sk.34371 Sisli/Istanbul, Turkey; E-mail: hkaozhan@gmail.com

Conflict of interest: There is no conflict of interest to declare.

Received 1 April 2019; Received in final form 28 May 2019; Accepted 25 June 2019. 
Carpal tunnel syndrome (CTS) is caused by entrapment of the median nerve travelling inside the carpal tunnel at the wrist. It is known as the most common focal entrapment mononeuropathy and represents $90 \%$ of all peripheral neuropathies ${ }^{1}$. The median nerve compression leads to nerve ischemia and results in alteration of neural conduction and nerve damage ${ }^{2}$. Patients with CTS typically complain of nighttime burning, paresthesias, and "pins-and-needles" pain in the fingers throughout the median nerve sensory distribution. Obesity, occupational exposure, older age, trauma, inflammatory rheumatic disorders, pregnancy, endocrine conditions such as hypothyroidism, acromegaly and diabetes mellitus, that reduce the carpal tunnel area or swell its contents, are risk factors for $\mathrm{CTS}^{3,4,5}$.

Examination of patients with CTS may reveal sensory complaints in the median-innervated digits and slight weakness of thumb abduction. Clinical testing for CTS includes provocation tests such as the Tinel's sign test (lightly tapping the flexor retinaculum) and Phalen test (increasing pressure in the carpal tunnel by wrist flexion for a minute). Electrophysiological nerve conduction tests and electromyography are widely used to determine median nerve compression severity. Carpal tunnel syndrome is diagnosed with a combination of symptoms, signs and nerve conduction testing ${ }^{6}$.

Treatment options for CTS are wrist splinting, non-steroidal anti-inflammatory drugs, diuretics, therapeutic ultrasound, local corticosteroid injections (LCIs) and carpal tunnel release surgery ${ }^{7}$. Although a high number of treatment modalities exist and are routinely used in the treatment of CTS, there are no accepted consensus guidelines for the treatment protocol of CTS. Carpal tunnel release surgery, cutting through the flexor retinaculum to reduce the pressure on the median nerve, is widely performed in severe cases where conservative treatments have failed. Even though carpal tunnel release surgery is mostly recommended for refractory cases, it has been observed that some patients may refuse to undergo carpal tunnel release surgery despite persistent symptoms after conservative therapy ${ }^{8,9}$. Because of technical advances in sonography examinations, ultrasound-guided carpal tunnel injections have become popular lately in selected patients. Ultrasound-guided injections for CTS may provide several clinical benefits such as locating the median nerve, and sonograms are non-invasive and convenient. However, to date, results of studies comparing the ultrasound-guided and blind injections for the treatment of CTS have been scarce.

Local corticosteroid injections generally contribute to greater clinical improvement in patients with mild-to-moderate $\mathrm{CTS}^{7,9,10}$. However, research evaluating the efficacy of LCIs is still under debate and a definitive consensus for the patients with severe CTS has not yet been reported ${ }^{7}$. In this study, we aimed to investigate the short-term clinical and electrophysiological outcomes and effectiveness of LCI on pain, sensory symptoms, and hand function in patients with mild, moderate and severe CTS.

\section{METHODS}

\section{Participants}

This retrospective cohort study was approved by the ethics committee of the University of Health Sciences, Sisli Hamidiye Etfal Research and Training Hospital, Istanbul, Turkey (Study Protocol Number: 1890) and was performed in accordance with the Declaration of Helsinki. Written informed consent was obtained from all participants. Consecutive patients with CTS who were admitted to our pain clinic during a 12-month period from June 2017 to June 2018 were enrolled in the study. Diagnosis of CTS was made on the basis of clinical symptoms, provocation tests (the Tinel's sign test, Phalen test, reverse Phalen test, and carpal compression test), electrophysiological findings and imaging studies of cervical structures to exclude other medical conditions if necessary. Only those patients who had not undergone any previous carpal tunnel releasing surgery were included. Furthermore, the patients with severe CTS according to electrodiagnostic findings were those who had refused surgery.

Inclusion criteria were:

1) patients' age older than 18 years;

2) nocturnal paresthesia; symptomatic relief after shaking the hands; pain, paresthesia or sensory symptoms in the area of the median nerve over the thumb and fingers;

3) symptoms for longer than one month;

4) idiopathic CTS;

5) mild to severe CTS, according to the CTS electrophysiological severity scale ${ }^{11}$.

Patients with the absence of median motor and sensory response in electrodiagnostic tests, patients with peripheral polyneuropathy, patients who had undergone previous surgery or LCI of the affected wrist, pregnant patients, and patients with cognitive impairment or other psychiatric disorders were excluded.

The patients' demographic characteristics: age, sex, income, education; hand dominance; symptoms such as numbness, pain, weakness, paresthesia; alleviating factors; onset of symptoms; additional disorders; history of trauma; neurological examinations; and post-injection complications were recorded.

A change in pain severity on the Numerical Rating Scale (NRS) was used to assess the response to the LCIs. The Boston Carpal Tunnel Syndrome Questionnaire, developed by Levine et al. ${ }^{12}$, was used to evaluate the severity of symptoms and functional status. The Boston Carpal Tunnel Syndrome Questionnaire has two sections: the Symptom Severity Scale (SSS) with 11 questions and the Functional Status Scale (FSS) with eight questions, which 
are completed by the patient. Every section contains five separate responses graded from 1 to 5 points. The Turkish translation of the Boston Carpal Tunnel Syndrome Questionnaire, whose validity and reliability had been assessed and confirmed by Sezgin et al. ${ }^{13}$, was administered.

The NRS, the SSS and the FSS, and nerve conduction studies were performed before, and three months after, the LCI.

\section{Electrophysiological evaluation}

Electrophysiological examinations were performed using the Medelec Synergy 10 channel (Oxford, UK) electromyography (EMG) machine. All measurements were carried out by the same neurophysiologist, while maintaining the skin temperature between $31^{\circ} \mathrm{C}$ and $34^{\circ} \mathrm{C}$. Conventional surface electrode techniques were used. Motor nerve conduction studies for the median nerve were recorded from the abductor pollicis brevis muscle at a distance of $8 \mathrm{~cm}$. Orthodromic sensory nerve conduction studies of the median nerve were stimulated from the index finger with ring electrodes and recorded at the wrist. In this position the distance from the stimulator was $14 \mathrm{~cm}$. The normal values used in our study were as follows:

1) Median nerve sensory peak latency; upper limit of normal $=3.6 \mathrm{~ms}$

2) Median nerve motor distal latency; upper limit of normal $=4.1 \mathrm{~ms}$

3) Median nerve motor conduction velocity; lower limit of normal $=49 \mathrm{~m} / \mathrm{s}$

4) Median nerve sensory conduction velocity; lower limit of normal $=49 \mathrm{~m} / \mathrm{s}$

5) Median nerve compound motor action potential (CMAP) amplitude; lower limit of normal $=4.9 \mathrm{mV}$.

The severity of CTS was classified into three groups: mild (prolonged median sensory peak latency and/or reduced median sensory velocity), moderate (prolonged median sensory peak latency and prolonged median motor distal latency), and severe (reduced median CMAP) ${ }^{11}$.

Needle EMG was performed if there was a suspicion of cervical radiculopathy or median axonal degeneration. All patients with severe CTS underwent needle EMG of the abductor pollicis brevis muscle. Ulnar nerve conduction studies were carried out routinely on all patients.

\section{Injection procedure}

The course of the medial flexor carpi radialis and palmaris longus tendons, $1 \mathrm{~cm}$ proximal to the distal palmar crease, was identified and marked. Following the preparation of the skin using an antiseptic solution, a $22 \mathrm{G}$ needle was inserted at 60 degrees to the skin surface. After negative aspiration, a mixture of local anesthetic $1 \mathrm{~mL}$ of $0.5 \%$ bupivacaine and $40 \mathrm{mg}(1 \mathrm{~mL})$ of methylprednisolone was injected on the volar side of the forearm between the tendons of the flexor carpi radialis muscle and palmaris longus muscle. Patients were then observed in the ward for a minimum of 30 minutes. Wrist splinting was suggested for all patients after the injection procedure.

\section{Statistical analysis}

The SPSS Statistics for Windows, version 23.0 (SPSS Inc., Chicago, Ill., USA) was used as the statistical analysis program. Descriptive statistics (mean, standard deviation, frequency, and percentage) were used for the demographic and clinical characteristics. The ANOVA with repeated measures test was used to compare follow-up outcome measures. Categorical data were compared using the chi-square test or Fisher's exact test. A p-value of $<0.05$ was considered to be statistically significant.

\section{RESULTS}

Twenty women and five men (45 wrists, 20 bilateral) with a mean age of $49.28 \pm 11.37$ years and an age range of 28-78 years were included in the current study. The mean duration of the symptoms was $2.29 \pm 0.99$ years. Details of the demographic and clinical characteristics of the study group are given in Table 1.

A lower income and level of education were significantly associated with a higher score on the SSS ( $p=0.008$ and $p=0.04$, respectively), NRS scores $(p=0.005$ and 0.017 , respectively), and FSS ( $p=0.008$ and $p=0.04$, respectively). Duration of symptoms and sex were not associated on the SSS ( $p=0.068$ and $p=0.059$, respectively), FSS ( $p=0.071$ and $p=0.069$, respectively) and NRS scores $(p=0.12$ and $p=0.22$, respectively) (all p-values $>0.05$ ). Patients with a positive Tinel's sign and Phalen's test had significantly higher scores on the NRS, SSS, and FSS ( $p=0.043$, $p=0.032$, $p=003$, respectively). Higher NRS and FSS scores were correlated with hand dominance $(p=0.01)$ and age $(p=0.021)$.

Mean NRS, SSS and FSS scores declined significantly three months after the LCI for all patient groups according to CTS severity (all p-values < 0.05). Comparison of changes in mean pre- and post-injection scores on the NRS, SSS and FSS is shown in Table 2. Duration of symptoms, age, sex, hand dominance, and level of education did not have any significant effect on the improvement on the SSS and FSS scores (all p-values > 0.05); however, an older age and longer duration were related to improved mean scores on the NRS $(p=0.041$ and $\mathrm{p}=0.044$ ). The three-month clinical evaluation showed a significant difference in terms of the Tinel's sign and positive Phalen's tests ( $p=0.023$ and $p=0.023$, respectively).

Changes in mean median nerve conduction study findings during the follow-up period are shown in Table 3. The comparison of patient groups using ANOVA variance analysis and post hoc studies evaluated the effects of the LCIs (Table 4). There was a significant decrease of sensory peak latency in the severe CTS group $(p=0.001)$. Post hoc testing for sensory peak latency showed a greater improvement 
Table 1. Demographic and clinical characteristics of the patients.

\begin{tabular}{|c|c|c|c|c|c|}
\hline \multirow{2}{*}{ Demographic/clinical characteristic } & \multirow{2}{*}{ Overall } & \multicolumn{3}{|c|}{ CTS Severity Groups } & \multirow{2}{*}{$p$-value } \\
\hline & & Mild & Moderate & Severe & \\
\hline Sex $(n) \star(F e m a l e /$ Male $)$ & $20 / 5$ & $17 / 2$ & $15 / 4$ & $6 / 1$ & $\star \star$ \\
\hline Number of wrists (n) & 45 (20 bilateral) & 19 & 19 & 7 & - \\
\hline Age* & $49.28 \pm 11.37$ & $47.84 \pm 12.72$ & $47.63 \pm 10.87$ & $57.71 \pm 11.37$ & 0.101 \\
\hline Duration of symptoms (years) & $2.29 \pm 0.99$ & $2.21 \pm 1.13$ & $2.10 \pm 0.73$ & $3.00 \pm 1.00$ & 0.111 \\
\hline \multicolumn{6}{|l|}{ Level of income $(n)^{\star}$} \\
\hline No income & 10 & 8 & 7 & 5 & \multirow{3}{*}{$\star \star$} \\
\hline Minimum wage & 9 & 8 & 7 & 1 & \\
\hline More than minimum wage & 6 & 3 & 5 & 1 & \\
\hline \multicolumn{6}{|l|}{ Level of education $(n)^{\star}$} \\
\hline Primary school & 3 & 2 & 1 & 3 & \multirow{3}{*}{$\star \star$} \\
\hline High school & 17 & 15 & 13 & 3 & \\
\hline University & 5 & 2 & 5 & 1 & \\
\hline
\end{tabular}

*In demographic variables (sex, age, level of income and education) some patients were classified in more than one CTS severity group due to having bilateral wrists with CTS; ${ }^{*}$ The number of patients within each category was not enough to conduct a chi-square test.

Table 2. Changes in mean pain severity, symptoms and functional status scores according to carpal tunnel syndrome severity.

\begin{tabular}{|c|c|c|c|c|c|}
\hline $\begin{array}{l}\text { Clinical } \\
\text { parameters }\end{array}$ & CTS severity groups & $\begin{array}{l}\text { Before LCl (mean } \pm \\
\text { SD) }\end{array}$ & $\begin{array}{l}3 \text { months after } \mathrm{LCl} \\
(\text { mean } \pm \mathrm{SD})\end{array}$ & $\begin{array}{l}\text { Within-group } \\
\text { comparison } \\
\text { (p-value)* }\end{array}$ & $\begin{array}{c}\text { Between-group } \\
\text { comparison } \\
(p-v a l u e)^{\star *}\end{array}$ \\
\hline & Mild & $7.89 \pm 0.66$ & $4.68 \pm 2.24$ & 0.000 & \\
\hline \multirow[t]{3}{*}{ NRS } & Moderate & $7.79 \pm 0.79$ & $3.26 \pm 1.59$ & 0.000 & 0.138 \\
\hline & Severe & $7.14 \pm 0.38$ & $3.00 \pm 2.45$ & 0.003 & \\
\hline & Mild & $37.26 \pm 6.05$ & $22.00 \pm 4.29$ & 0.000 & \\
\hline \multirow[t]{3}{*}{ SSS } & Moderate & $34.37 \pm 4.31$ & $21.21 \pm 3.77$ & 0.000 & 0.533 \\
\hline & Severe & $31.43 \pm 3.15$ & $18.86 \pm 3.44$ & 0.001 & \\
\hline & Mild & $28.11 \pm 4.43$ & $17.79 \pm 4.02$ & 0.000 & \\
\hline \multirow[t]{2}{*}{ FSS } & Moderate & $26.58 \pm 5.84$ & $17.68 \pm 6.01$ & 0.000 & 0.690 \\
\hline & Severe & $24.29 \pm 3.25$ & $13.86 \pm 4.34$ & 0.001 & \\
\hline
\end{tabular}

CTS: carpal tunnel syndrome; LCI: local corticosteroid injection; NRS: Numerical Rating Scale; SSS: Symptom Severity Scale; FSS: Functional Status Scale; SD: standard deviation; *Paired $t$ test was used for before/after comparison; **Analysis of variance was used for comparing patient groups according to CTS severity.

Table 3. Changes in mean/median nerve conduction study findings at the follow-up according to the severity of the carpal tunnel syndrome groups.

\begin{tabular}{|c|c|c|c|c|c|}
\hline $\begin{array}{l}\text { Neurophysiological } \\
\text { parameters }\end{array}$ & CTS severity groups & $\begin{array}{c}\text { Before LCl } \\
(\text { mean } \pm \text { SD) }\end{array}$ & $\begin{array}{c}3 \text { months after } \mathrm{LCl} \\
(\text { mean } \pm \mathrm{SD})\end{array}$ & $\begin{array}{c}\text { Within-group } \\
\text { comparison } \\
(p \text {-value })^{\star}\end{array}$ & $\begin{array}{c}\text { Between-group } \\
\text { comparison } \\
(p \text {-value })^{\star *}\end{array}$ \\
\hline \multirow{3}{*}{$\begin{array}{l}\text { Sensory peak } \\
\text { latency }\end{array}$} & Mild & $3.67 \pm 0.71$ & $3.53 \pm 0.72$ & 0.188 & \multirow{3}{*}{0.023} \\
\hline & Moderate & $3.90 \pm 0.46$ & $3.56 \pm 0.50$ & 0.023 & \\
\hline & Severe & $4.66 \pm 0.89$ & $3.89 \pm 0.64$ & 0.001 & \\
\hline \multirow{3}{*}{ Sensory velocity } & Mild & $42.31 \pm 7.07$ & $45.58 \pm 7.47$ & 0.043 & \multirow{3}{*}{0.984} \\
\hline & Moderate & $41.25 \pm 5.31$ & $44.93 \pm 7.45$ & 0.026 & \\
\hline & Severe & $34.00 \pm 8.60$ & $37.57 \pm 8.83$ & 0.401 & \\
\hline \multirow{3}{*}{$\begin{array}{l}\text { Motor distal } \\
\text { latency }\end{array}$} & Mild & $3.52 \pm 0.26$ & $3.74 \pm 0.52$ & 0.060 & \multirow{3}{*}{0.000} \\
\hline & Moderate & $4.70 \pm 0.46$ & $4.02 \pm 0.74$ & 0.002 & \\
\hline & Severe & $7.21 \pm 1.89$ & $5.39 \pm 1.07$ & 0.005 & \\
\hline \multirow{3}{*}{ CMAP amplitude } & Mild & $9.09 \pm 1.97$ & $9.04 \pm 2.43$ & 0.891 & \multirow{3}{*}{0.073} \\
\hline & Moderate & $8.46 \pm 2.55$ & $8.64 \pm 1.73$ & 0.689 & \\
\hline & Severe & $4.67 \pm 1.99$ & $6.57 \pm 2.77$ & 0.050 & \\
\hline \multirow{3}{*}{ Motor velocity } & Mild & $51.95 \pm 7.43$ & $57.11 \pm 3.98$ & 0.013 & \multirow{3}{*}{0.006} \\
\hline & Moderate & $56.69 \pm 5.38$ & $54.36 \pm 5.42$ & 0.074 & \\
\hline & Severe & $48.57 \pm 3.91$ & $51.29 \pm 4.15$ & 0.325 & \\
\hline
\end{tabular}

LCI: local corticosteroid injection; CTS: carpal tunnel syndrome; SD: standard deviation; CMAP: compound motor action potential; *Paired t test was used for before/after comparison; **Analysis of variance was used for comparing patient groups according to CTS severity. 
Table 4. Post hoc analysis for comparing changes in neurophysiological parameters between patient groups according to CTS severity.

\begin{tabular}{lcc|}
\hline $\begin{array}{l}\text { Neurophysiological } \\
\text { parameters }\end{array}$ & CTS severity & $\begin{array}{c}\text { Pairwise } \\
\text { comparison } \\
(\mathrm{p} \text {-value)* }\end{array}$ \\
\hline Sensitive peak & Mild vs Moderate & 0.423 \\
latency & Mild vs Severe & 0.017 \\
& Moderate vs Severe & 0.141 \\
Motor distal latency & Mild vs Moderate & 0.001 \\
& Mild vs Severe & 0.000 \\
& Moderate vs Severe & 0.003 \\
Motor velocity & Mild vs Moderate & 0.005 \\
& Mild vs Severe & 0.231 \\
& Moderate vs Severe & 0.701
\end{tabular}

CTS: carpal tunnel syndrome; *Tukey test was used for pairwise comparison of patient groups according to CTS severity.

in the severe CTS group than the patients with mild CTS $(p=0.017)$. Sensory velocity increased significantly in the mild and moderate CTS groups $(\mathrm{p}=0.043$ and $\mathrm{p}=0.023$, respectively); however, there was no significant difference between the three groups. Motor distal latency decreased significantly in the moderate and severe CTS groups and the means of the three groups differed significantly (all $\mathrm{p}$-values $<0.05)$. Motor velocity increased significantly only in the mild CTS group ( $\mathrm{p}=0.013$ ). No significant improvement was detected for CMAP values in the three groups after LCI (all p-values > 0.05).

There was no relationship between median nerve conduction study findings, demographic characteristics, and the clinical evaluation, while a younger age was related to a significant increase in sensory conduction velocity, but there were no significant changes in any of the other neurophysiologic parameters by the third month after the injection ( $\mathrm{p}=0.037)$.

Age showed a negative correlation with the change of mean NRS scores $(\mathrm{p}=0.033 ; \mathrm{r}=-0.319)$. After injection, older patients had a lower pain severity. In addition, there was a significant negative correlation between age and sensory velocity ( $p=0.037 ; r=0 .-312)$. However, neither level of income, education, nor duration of symptoms showed a correlation with changes in mean pain severity, symptoms and functional status scores and neurophysiological parameters.

The severity of CTS according to electrodiagnostic findings before and after LCI injection is given in Table 5. Before injection, there were 19 patients with mild CTS, 19 patients with moderate CTS, and seven patients with severe CTS. After LCI injection, the number of patients with mild CTS increased from 19 to 25 , and the number of patients with moderate and severe CTS decreased.

Most post-injection complications were minor and transient. Complications were as follows: 12 patients had
Table 5. Carpal tunnel syndrome severity according to electrodiagnostic findings before and after local corticosteroid injection.

\begin{tabular}{lcc}
\hline CTS severity & Before $\mathrm{LCl}(\mathrm{n})$ & 3 months after $\mathrm{LCl}(\mathrm{n})$ \\
\hline Mild & 19 & 25 \\
Moderate & 19 & 14 \\
Severe & 7 & 6 \\
\hline CTS: carpal tunnel syndrome; LCl: local corticosteroid injection.
\end{tabular}

CTS: carpal tunnel syndrome; LCl: local corticosteroid injection.

temporary numbness, four patients reported increased pain on the injection day, four patients had wrist flexor or extensor weakness and three patients had pain at the injection site. Infection, hematoma, paralysis, and nerve injury were not reported.

\section{DISCUSSION}

This study aimed to demonstrate the outcomes pertaining to the management of CTS after performing a local injection using a mixture of corticosteroid and local anesthetics at a three-month follow-up. After treatment, changes of sensory conduction velocities, sensory peak latency, and motor distal latency were found to be statistically significant. Based on the statistical significance and clinical effectiveness, the results of this study suggest that local injection of a corticosteroid in the treatment of CTS is effective and safe in the reduction of pain intensity and symptom severity, contributing to increasing functioning of the hand. The effectiveness of treatment continued throughout the follow-up period. Although LCIs are considered in most patients with mild-to-moderate CTS ${ }^{14}$, our findings showed that patients who refuse surgical intervention may benefit from the injection. A number of randomized controlled trials have documented the treatment efficacy of LCI in patients with mild and moderate $\mathrm{CTS}^{7,10,15}$. We found that improvement of mean pain severity, symptoms and functional status scores did not differ between mild, moderate and severe CTS patient groups. All the groups had better clinical outcomes after injection at the three-month follow-up. The results of the current study support that LCI might be considered for patients with more advanced CTS in any case of contraindication to surgery. Our findings of the relationship between the clinical and demographic characteristics and electrodiagnostic studies before the procedure concur with the previously-published literature ${ }^{7,10,16}$. Despite the fact that the demographic characteristics of the patients did not show an association with symptom severity and functioning, the procedure resulted in the improvement of pain intensity in patients with an older age. This may be explained by the fact that, in this study group, compared with older patients, young patients were more often employed, and they may have suffered 
traumatic and repeated injuries. In the current study, it was found that younger age was correlated with a significant increase in sensory conduction velocity. Myelin dysfunction due to entrapment of the median nerve is responsible for reduced conduction velocity ${ }^{17}$. The LCI into the carpal tunnel may reduce tendon swelling, edema, and tissue pressure, and lead to remyelination ${ }^{18}$. The ability of the fibers to remyelinate is faster in younger patients than in older patients with CTS. This may be the reason for the significant increase in sensory conduction velocity in our young patient sample following LCI.

Nerve ultrasound is a useful and painless screening tool. In a single-blind prospective trial by Ustun et al., the authors reported that the ultrasound-guided injection group had greater improvements in symptom severity scores than the direct injection group at the three-month follow-up ${ }^{16}$. Lee et al. evaluated the degree of symptom improvement after sonographically-guided and blind local steroid injections. After 12 weeks, they found that there was no significant difference in symptom severity scores between the out-plane ultrasound-guided injection and direct injection groups ${ }^{19}$. In a double blind randomized controlled trial, Chen et al. assessed the effectiveness of ultrasound-guided versus direct-approach injections for $\mathrm{CTS}^{15}$. They reported that they did not observe any difference in the clinical evaluation of the outcomes of the two groups, similar to the findings of Lee et al. Ulnar approaches between the palmaris longus and flexor carpi radialis tendons, or just medial to the palmaris longus tendon, have commonly been performed as a successful blind injection technique for CTS treatment ${ }^{20-22}$. The improvement in clinical evaluation in the current study is in accordance with previous studies ${ }^{2,11,15,16}$. In our sample, most post-injection complications were minor and transient. However, in the practice of blind injections, there is a risk of serious complications such as nerve and artery injury and hematoma. For this reason, we highly recommend these procedures be performed by experienced physicians.

The treatment of patients with CTS requires a generalized approach with pharmacologic, physical, and surgical treatment, including conservative and interventional therapies such as anesthetic block, corticosteroid injection, and carpal tunnel release surgery ${ }^{7,23}$. In a randomized clinical trial by So et al., researchers compared local steroid injection versus wrist splinting for their short-term clinical effects on $\mathrm{CTS}^{24}$. They found a significant improvement in the SSS scores in both the steroid group and splinting group, four weeks after treatment. However, no improvement was found in the finger dexterity test in the splinting group. On the other hand, Sevim et al. compared the long-term effectiveness of steroid injections and splinting in mild and moderate CTS, and stated that only splinting provided symptomatic relief while injections of steroids were ineffective at the one-year follow-up ${ }^{25}$. Although wrist splints used as adjuvant treatment seem to improve pain, in spite of any significant evidence in the Cochrane Database analysis ${ }^{26}$, in our experience, wrist splints helped patients with CTS to become more aware of their injured hand while using it in their daily life. For this reason, after injection, all participants of this study were encouraged to use splints. The decision of the types of steroids and local anesthetics, and their appropriate dosages for the treatment of CTS, still remains controversial. There have been studies reporting the efficacy of LCIs at different dosages in patients with $\mathrm{CTS}^{27-29}$. In their randomized controlled trial, Karimzadeh et al. reported that $20 \mathrm{mg}$ triamcinolone and $40 \mathrm{mg}$ methylprednisolone had provided a significant improvement in pain and functional status ${ }^{29}$. Due to different study designs and features of patients with CTS in the current literature, the most efficient type of steroid and its dosage is unclear. Methylprednisolone and triamcinolone are the most popular corticosteroids used for local injections in patients with $\mathrm{CTS}^{30}$. In addition, there is inadequate evidence for the best choice of local anesthetic and its dose. In the current study, we performed LCIs using a mixture of a long-acting amide local anesthetic (bupivacaine) and methylprednisolone. This combination had been reported to provide an excellent and long-lasting analgesia for the management of pain. Mirzai et al. reported that a mixture of corticosteroids and bupivacaine lowered the incidence of back pain after laminectomy in the postoperative period $^{31}$. Intrathecal administration of methylprednisolone with bupivacaine was found to decrease the pain scores in patients with postherpetic neuralgia ${ }^{32}$.

According to the American Academy of Orthopedic Surgeons' clinical practice guideline on the treatment of CTS, electrodiagnostic tests and clinical evaluation are recommended for the diagnosis of CTS and decision making for carpal tunnel release surgery ${ }^{33}$. Surgery is generally inappropriate for mild-to-moderate symptoms without electrodiagnostic confirmation and previously-attempted conservative treatment. For severe symptoms, surgery is broadly indicated where there is an abnormal electrophysiological assessment or unsuccessful conservative treatment options ${ }^{34}$. Comparison of LCI and surgical interventions have been undertaken in several studies. Ly-Pen et al. compared the one-year follow-up effects of local steroid injection and surgical decompression and reported that LCIs provided a better clinical improvement in the short term, while it was as effective as surgical decompression after one year ${ }^{35}$. Gurcay et al. investigated the effectiveness of LCI and surgery in the treatment of patients with severe CTS. They reported that LCI and surgical decompression achieved significant clinical and electrophysiological improvements within a three-month period without superiority of one treatment over other ${ }^{36}$. The authors recommended that LCI could be applied as a less-invasive treatment alternative in patients with severe CTS. Favorable improvements in the clinical evaluation were found in patients with severe CTS in the present study. Our findings support that LCI might be a promising treatment 
option in patients with severe CTS for whom surgical decompression cannot be considered.

Lack of a control group is an important limitation of this study. The use of a placebo control in any neural intervention is a difficult task, adding ethical issues and difficulties. In addition, because of the subjective nature of the NRS, symptom severity and functional status questionnaire scores, pain experienced by patients during the treatment period may not be reflected objectively. However, determining the improvement in median nerve conduction studies and traditional physical examination measures are the strength of the current study. The difference in the current research from other studies is the evaluation of the effects of LCI for patients with severe CTS.

Although the relatively-short duration of follow-up limits the significance of our results, we conclude that blind CTS injections with a mixture of local anesthetics and methylprednisolone are a safe, simple, and effective technique, without serious and permanent adverse effects. Because of the heterogeneity of techniques for the treatment of CTS, LCIs may be considered as a useful treatment option for patients with CTS who have failed conservative treatments. Furthermore, LCI therapy may be considered as a treatment alternative for patients with moderate and severe CTS who refuse to undergo surgery. A longer-term follow-up of participants would be required to determine how long the effects would last.

\section{Acknowledgments}

The authors thank Mr Mustafa Cem Ertem for his statistical assistance.

\section{References}

1. Sternbach G. The carpal tunnel syndrome. J Emerg Med. 1999 MayJun;17(3):519-23. https://doi.org/10.1016/S0736-4679(99)00030-X

2. Harris-Adamson C, Eisen EA, Kapellusch J, Garg A, Hegmann KT, Thiese MS, et al. Biomechanical risk factors for carpal tunnel syndrome: a pooled study of 2474 workers. Occup Environ Med. 2015 Jan;72(1):33-41. https://doi.org/10.1136/oemed-2014-102378

3. Alsharif AA, Nasir F, Shi Y, Tian X, Khan AA, Guo YJ. Risk factors, diagnosis, and treatments for carpal tunnel syndrome: a review. Science Letters. 2017;5(3):233-43.

4. Viera AJ. Management of carpal tunnel syndrome. Am Fam Physician. 2015;68(2):265-72.

5. Aboong MS. Pathophysiology of carpal tunnel syndrome. Neurosciences (Riyadh). 2015 Jan;20(1):4-9.

6. Newington L, Harris EC, Walker-Bone K. Carpal tunnel syndrome and work. Best Pract Res Clin Rheumatol. 2015 Jun;29(3):440-53. https://doi.org/10.1016/j.berh.2015.04.026

7. O'Connor D, Marshall S, Massy-Westropp N, Pitt V. Non-surgical treatment (other than steroid injection) for carpal tunnel syndrome. Cochrane Database Syst Rev. 2003;(1):CD003219. https://doi.org/10.1002/14651858.CD003219

8. Al-Qattan M, Bowen V. Patients refusing to undergo carpal tunnel release despite persistent symptoms after conservative therapy. Can J Plast Surg. 1994;2(4):171-2. https://doi.org/10.1177/229255039400200411

9. Shifflett GD, Dy CJ, Daluiski A. Carpal tunnel surgery: patient preferences and predictors for satisfaction. Patient Prefer Adherence. 2012;6:685-9.

10. Agarwal V, Singh R, Sachdev A, Wiclaff, Shekhar S, Goel D. A prospective study of the long-term efficacy of local methyl prednisolone acetate injection in the management of mild carpal tunnel syndrome. Rheumatology (Oxford). 2005 May;44(5):647-50. https://doi.org/10.1093/rheumatology/keh571

11. Padua L, LoMonaco M, Gregori B, Valente EM, Padua R, Tonali P. Neurophysiological classification and sensitivity in 500 carpal tunnel syndrome hands. Acta Neurol Scand. 1997 Oct;96(4):211-7. https://doi.org/10.1111/j.1600-0404.1997.tb00271.x

12. Levine DW, Simmons BP, Koris MJ, Daltroy LH, Hohl GG, Fossel $\mathrm{AH}$, et al. A self-administered questionnaire for the assessment of severity of symptoms and functional status in carpal tunnel syndrome. J Bone Joint Surg Am. 1993 Nov;75(11):1585-92 https://doi.org/10.2106/00004623-199311000-00002
13. Sezgin M, Incel NA, Serhan S, Camdeviren H, As I, Erdoğan C. Assessment of symptom severity and functional status in patients with carpal tunnel syndrome: reliability and functionality of the Turkish version of the Boston Questionnaire. Disabil Rehabil. 2006 Oct;28(20):1281-5. https://doi.org/10.1080/09638280600621469

14. Sonoo M, Menkes DL, Bland JD, Burke D. Nerve conduction studies and EMG in carpal tunnel syndrome: do they add value? Clin Neurophysiol Pract. 2018 Apr;3:78-88. https://doi.org/10.1016/j.cnp.2018.02.005

15. Chen PC, Wang LY, Pong YP, Hsin YJ, Liaw MY, Chiang CW. Effectiveness of ultrasound-guided vs direct approach corticosteroid injections for carpal tunnel syndrome: A double-blind randomized controlled trial.J Rehabil Med. 2018 Feb;50(2):200-8. https://doi.org/10.2340/16501977-2308

16. Ustün N, Tok F, Yagz AE, Kizil N, Korkmaz I, Karazincir S, et al. Ultrasound-guided vs. blind steroid injections in carpal tunnel syndrome: A single-blind randomized prospective study. Am J Phys Med Rehabil. 2013 Nov;92(11):999-1004. https://doi.org/10.1097/PHM.0b013e31829b4d72

17. Jablecki CK, Andary MT, Floeter MK, Miller RG, Quartly CA, Vennix MJ, et al. Practice parameter: Electrodiagnostic studies in carpal tunnel syndrome. Report of the American Association of Electrodiagnostic Medicine, American Academy of Neurology, and the American Academy of Physical Medicine and Rehabilitation. Neurology. 2002 Jun;58(11):1589-92. https://doi.org/10.1212/WNL.58.11.1589

18. Chen PC, Chuang CH, Tu YK, Bai CH, Chen CF, Liaw M. A Bayesian network meta-analysis: comparing the clinical effectiveness of local corticosteroid injections using different treatment strategies for carpal tunnel syndrome. BMC Musculoskelet Disord. 2015 Nov;16(1):363. https://doi.org/10.1186/s12891-015-0815-8

19. Lee JY, Park Y, Park KD, Lee JK, Lim OK. Effectiveness of ultrasound-guided carpal tunnel injection using inplane ulnar approach: a prospective, randomized, singleblinded study. Medicine (Baltimore). 2014 Dec;93(29):e350. https://doi.org/10.1097/MD.0000000000000350

20. Ozturk K, Esenyel CZ, Sonmez M, Esenyel M, Kahraman S, Senel B. Comparison of carpal tunnel injection techniques: a cadaver study. Scand J Plast Reconstr Surg Hand Surg. 2008;42(6):300-4. https://doi.org/10.1080/02844310802401363

21. Wood MR. Hydrocortisone injections for carpal tunnel syndrome. Hand. 1980 Feb;12(1):62-4. https://doi.org/10.1016/S0072-968X(80)80031-3PMID:6154006 
22. Frederick HA, Carter PR, Littler JW. Injection

injuries to the median and ulnar nerves at the wrist.

J Hand Surg Am. 1992 Jul;17(4):645-7.

https://doi.org/10.1016/0363-5023(92)90309-D

23. Martins RS, Siqueira MG. Conservative therapeutic management of carpal tunnel syndrome. Arq Neuropsiquiatr. 2017 Nov;75(11):819-24. https://doi.org/10.1590/0004-282×20170152

24. So H, Chung VC, Cheng JC, Yip RM. Local steroid injection versus wrist splinting for carpal tunnel syndrome: A randomized clinical trial. Int J Rheum Dis. 2018 Jan;21(1):102-7. https://doi.org/10.1111/1756-185X.13162

25. Sevim S, Dogu O, Camdeviren H, Kaleagasi H, Aral M. Arslan E, et al. Long-term effectiveness of steroid injections and splinting in mild and moderate carpal tunnel syndrome. Neurol Sci. 2004 Jun;25(2):48-52. https://doi.org/10.1007/s10072-004-0229-0PMID:15221621

26. Page MJ, Massy-Westropp N, O'Connor D, Pitt V. Splinting for carpal tunnel syndrome. Cochrane Database Syst Rev. 2012 Jul;(7):CD010003. https://doi.org/10.1002/14651858.CD010003

27. Delaunay L, Chelly JE. Blocks at the wrist provide effective anesthesia for carpal tunnel release. Can J Anaesth. 2001 Jul-Aug;48(7):656-60. https://doi.org/10.1007/BF03016199

28. Dammers JW, Roos Y, Veering MM, Vermeulen M. Injection with methylprednisolone in patients with the carpal tunnel syndrome: a randomised double blind trial testing three different doses. J Neurol. 2006 May;253(5):574-7. https://doi.org/10.1007/s00415-005-0062-2

29. Karimzadeh A, Bagheri S, Raeissadat SA, Bagheri S, Rayegani SM, Rahimi-Dehgolan S, et al. The comparison of the effectiveness between different doses of local methylprednisolone injection versus triamcinolone in Carpal Tunnel Syndrome: a double-blind clinical trial.J Pain Res. 2019 Feb;12:579-84. https://doi.org/10.2147/JPR.S190652
30. Salman Roghani R, Holisaz MT, Tarkashvand M, Delbari A, Gohari F, Boon AJ, et al. Different doses of steroid injection in elderly patients with carpal tunnel syndrome: a triple-blind, randomized, controlled trial. Clin Interv Aging. 2018 Jan;13:117-24. https://doi.org/10.2147/CIA.S151290

31. Mirzai H, Tekin I, Alincak H. Perioperative use of corticosteroid and bupivacaine combination in lumbar disc surgery: a randomized controlled trial. Spine. 2002 Feb;27(4):343-6. https://doi.org/10.1097/00007632-200202150-00003

32. Kotani N, Kushikata T, Hashimoto H, Kimura F, Muraoka M, Yodono M, et al. Intrathecal methylprednisolone for intractable postherpetic neuralgia. N Engl J Med. 2000 Nov;343(21):1514-9. https://doi.org/10.1056/NEJM200011233432102

33. Keith MW, Masear V, Chung KC, Amadio PC, Andary M, Barth RW, et al.; American Academy of Orthopaedic Surgeons. American Academy of Orthopaedic Surgeons clinical practice guideline on the treatment of carpal tunnel syndrome. J Bone Joint Surg Am. 2010 Jan;92(1):218-9. https://doi.org/10.2106/JBJS.I.00642

34. Maggard MA, Harness NG, Chang WT, Parikh JA, Asch SM, Nuckols TK; Carpal Tunnel Quality Group. Indications for performing carpal tunnel surgery: clinical quality measures. Plast Reconstr Surg. 2010 Jul;126(1):169-79. https://doi.org/10.1097/PRS.0b013e3181da8685

35. Ly-Pen D, Andréu JL, Blas G, Sánchez-Olaso A, Millán I. Surgical decompression versus local steroid injection in carpal tunnel syndrome: a one-year, prospective, randomized, open, controlled clinical trial. Arthritis Rheum. 2005 Feb;52(2):612-9. https://doi.org/10.1002/art.20767

36. Gurcay AG, Karaahmet OZ, Gurcan O, Kazanci A, Karsli PB, Umay EK, et al. Comparison of short-term clinical and electrophysiological outcomes of local steroid injection and surgical decompression in the treatment of carpal tunnel syndrome. Turk Neurosurg. 20171;27(3):447-52. https://doi.org/10.5137/1019-5149.JTN.15936-15.0 